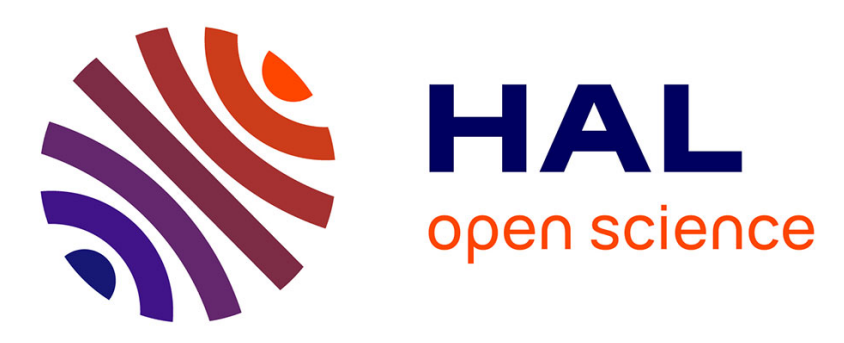

\title{
How Can Technology Support Education in War - WarAware Education Platform for Syria
}

\author{
Nada Almasri, Luay Tahat, Laila Al Terkawai
}

\section{To cite this version:}

Nada Almasri, Luay Tahat, Laila Al Terkawai. How Can Technology Support Education in War WarAware Education Platform for Syria. 17th Conference on e-Business, e-Services and e-Society (I3E), Oct 2018, Kuwait City, Kuwait. pp.436-448, 10.1007/978-3-030-02131-3_39 . hal-02274168

\section{HAL Id: hal-02274168 \\ https://hal.inria.fr/hal-02274168}

Submitted on 29 Aug 2019

HAL is a multi-disciplinary open access archive for the deposit and dissemination of scientific research documents, whether they are published or not. The documents may come from teaching and research institutions in France or abroad, or from public or private research centers.
L'archive ouverte pluridisciplinaire HAL, est destinée au dépôt et à la diffusion de documents scientifiques de niveau recherche, publiés ou non, émanant des établissements d'enseignement et de recherche français ou étrangers, des laboratoires publics ou privés. 


\title{
How Can Technology Support Education in War - War- Aware Education Platform for Syria
}

\author{
Nada Almasri ${ }^{1}$, Luay Tahat ${ }^{1}$, Laila Al Terkawai ${ }^{1}$ \\ ${ }^{1}$ Department of Management Information Systems, \\ ${ }^{1}$ Gulf University for Science and Technology, West Mishref, Kuwait \\ Almasri.n@gust.edu.kw, tahat.l@gust.edu.kw, alterkawai@gust.edu.kw
}

\begin{abstract}
The well-known Syria crisis has made it very challenging for thousands of Syrian children to have access to education. In this paper, we propose digital education platform to allow displaced Syrian kids as well as kids in the refugee camps in bordering countries, to have access to education. The proposed platform consists of four pillars: Hardware, Software, Curriculum, and Support services. We start by looking at the efforts performed in the field of education in war situations, and we extract from them the lessons learned and recommendations. We provide four main characteristics of war impacting kids' education: (1) insecurity, (2) instability, (3) lack of resources, and (4) lack of adults' supervision. We then use these four characteristics along with the extracted recommendations, as the grounds for drafting three design considerations for the implementation of a digital education platform. The three design considerations are supervised self-directed learning method, context-aware education, and kids-oriented design. Finally, we use these design considerations to provide design recommendations for the four pillars of the platform. We conclude our work by discussing the validity of the platform, its implementation feasibility, and challenges facing the implementation.
\end{abstract}

Keywords. Education in war; education in emergencies; war characterization; supervised self-directed learning; digital learning platform for kids; design considerations; context-aware education; kids-oriented design.

\section{Introduction}

War impacts all aspects of the society. It impacts the economic, the social life, the psychosocial stability of the population, the educational system, and all other aspects. The interplay between all of these affected aspects drastically impact kids. The interplay between the impact of war on the educational system and the impact of war on kids play an important role in defining the educational challenges facing kids in war situations.

The impact of war on kids goes way beyond its impact on adults. While adults have reached the point where they already have shaped personalities, established judgment/moral inner-system, and some level of base-knowledge of life/career skills; kids, who represent the future of the society in the post-conflict period, are yet to build all of these aspects of their lives. This developmental process is already complex, and war conditions make it even more challenging with the risk of long-term negative impacts on one's self, the society, as well as future generations. The impact of war on kids ranges from direct physical impact to indirect and long-term impact. As direct impact, kids may suffer from disabilities caused by war injuries, they may lose one or both of 
their parents; the primary caregivers for them, and they would live in distress caused by the sense of insecurity and instability encountered during war. Moreover, kids who lost their primary caregivers, are at higher risks of different kinds of exploitation such as child labour, sexual abuse, and recruitment in armed forces. A child growing up in such circumstances of war may suffer as an adult from long lasting psychological impacts such as post-traumatic stress disorder.

As for the impact of war on education, it is reported by the UNESCO that in war affected areas, the educational system is deliberately targeted [1]. UNESCO reports that over a period of three years (2007 to 2009), at least 31 countries had their educational system deliberately attacked by rebels, armies or repressive regimes. During war, the educational infrastructure is destroyed, teachers are either killed or displaced, and fewer funding for schools supplies is provided by authorities and by parents who prioritize funding survival related tasks such as safety, food, health, and shelter. Targeting the educational system during war results in decreased access to schools, the degradation of the quality of education, and the lower educational attainment [2], [3].

This combined impact of war on kids and on education makes it challenging for kids to pursue their education, which plays an important role in shaping their personalities and in determining their future success in life. Indeed, at the long term, studies in criminology found negative correlation between educational attainment and crime [4], [5]. Studies in education found that youth delinquent behaviour can be associated to early childhood factors which can be lessened with well-designed early childhood education [6]. Thus, the UNESCO emphasize the critical role of education in post-conflict stability of the community [7], [8]. Indeed, education is being considered as the fourth pillar when responding to humanitarian crisis following food, shelter, and healthcare [9].

With respect to Syria crisis, the UNICEF reports that the number of children affected by Syria Crisis is six-million children, among which almost 2,800,000 are displaced children, and two-million children are located in hard to reach areas, while 133,000 children under siege in eastern Aleppo area only. Over two-million children are out of school in Syria, and over 700,000 Syrian refugee children are out of any form of education in neighbouring countries [10].

While the war situation makes it challenging to offer conventional educational systems, the rapid advances in information and communication technology can greatly help. Indeed, technology is rapidly advancing in different fields: Hardware, software, and telecommunication. With these advances in technological aspects, we increasingly see all non-technical fields integrating technology to enhance their effectiveness. Medicine, Art, and Education are among these fields which are greatly benefiting from technology integration.

In war-affected areas, the United Nations (UN) agencies as well as several non-governmental organizations (NGOs) have initiated different projects and initiatives to use technology for the implementation of educational platforms [11]. Given the emergency nature of the implementation of these educational systems, little efforts were done to ground these projects on research-based concepts. Additionally, little was done to implement a mechanism to measure the impact of these projects, and ways to adapt them at a higher scale. The main critics received about these projects is that they focused on 
the technology itself, and they placed little emphasis on more critical educational components such as the curriculum, the learning environment, and the adaption of the technology to serve the particular needs of kids in war-affected areas.

In this paper, we start section 2 by looking at the efforts performed in the field of education in war affected areas, and we extract from them the lessons learned and recommendations. In section 3, we provide four main characteristics of war, and we look at their impact on children and their education. In section 4, we use these four characteristics along with the extracted recommendations, as the grounds for drafting three design considerations for the implementation of context-aware digital education platform. Finally, section 5 lays out the four pillars of the platform: Hardware, Software, Curriculum, and Supporting Services.

\section{Efforts performed in the field of Education in emergencies}

In this section, we explore the work done in the field of education in war. We consider research papers and reports, as well as projects and initiatives. The work considered is focused on work which gives insights on educational challenges in war situation in general or in Syria crisis context in particular.

\subsection{Machel Report}

The Machel report is an expert report released by the secretary-general of the UN in 1996. It addressed the impact of armed conflict on children, and it presented an action plan to improve child protection in war zones [7]. The report which was prepared by Graca Machel, was later followed up by a book in 2001 to assess the actions taken in response to the recommendations of the 1996 report and to extend it with further insights and recommendations [9].

Among other issues, Machel addressed the psychological impact of war on kids, and she viewed education as means of survival. Her recommendations addressing these two areas focus on providing educational and psychosocial support for children as an integral part of all humanitarian efforts, and she emphasizes the importance of educating the children in ware-related issues such as landmine and peace education. Finally, she encourages involving the community in curriculum planning to ensure that it is childrights based and locally relevant.

\subsection{Learning for a Future}

The UNHCR published a book compiling a collection of five literature review papers presented at 2001 workshop "Refugee Education in Developing Countries: Policy and Practice" [11]. The book addresses education in emergencies, quality and attainment in refugee schools, peace education for refugee youth, and vocational training for refugees. The book gives insights and general recommendations for efforts targeting refugee education.

The book formulates the basic principles of education in emergencies as: adopting community-based approach and capacity-building; training refugee teachers, youth leaders, and refugee schools administrators; meeting psychological need of the children; providing rapid response to educational needs; emphasizing durable solutions; encouraging 
regional approach to certification; integrating survival, peace-building, and citizenship messages, broadening the education to consider a verity of groups, and promoting interagency cooperation.

\subsection{The Quantitative Impact of Conflict on Education}

UNISCO institute for statistics released a commissioned report in 2011 evaluating the quantitative impact of conflict on education in 25 countries touched by armed conflicts. The study measured schooling and retention by looking at the share of the population without formal schooling and the average number of years of formal education. The study didn't include Syria as it was conducted in the same year of the Syrian uprising. In general, the study found significant negative impact of conflict on the proportion of the population with formal education, the average years of education attained, and the literacy rate. Additionally, the study found that "cohorts that were of school-going age during a time of conflict have lower educational attainment that persists over time, indicating that these children generally do not resume their education after a conflict to attain levels of education similar to non-exposed cohorts" [3].

\subsection{Innovation Labs}

"Innovation at UNHCR 2014" is a report presented by the UNHRCR innovation unit. It highlights the five pillars which form the framework around which the unit operates. Innovation labs are one of these five pillars. They "apply principles of human-centred design and prototyping to address complex refuges challenges" [13]. The report highlights the five-step approach to developing projects by the unit. The five steps are defining the challenges, identify solutions, test solutions, refine solutions, and scale solutions. The project they address are around five themes: learn, home, link, and energy. The learn theme is focused on expanding education opportunities for refugees and displaced people. Under this themes, the report lists six projects in different conflict-affected countries (but they don't include Syria) without providing any further details about the projects. One of the most interesting sections of the report is the lessons learned section. The five key lesson they highlight are: Senior management engagement in the field prior to implementation, embedding new projects with ongoing education strategies instead of independent projects, engaging youth and the community in the design process, having dedicated staff, and securing multi-year funding.

\subsection{Barriers to Education in Conflict-Affected Countries}

Another paper commissioned by the UNESCO institute for statistics was released in 2014 to shed the light on educational challenges during war, and to "suggest policy interventions to break barriers to the implementation and effectiveness of education systems" [8].

The report distinguishes between supply-side barriers and demand-side barriers. Supply-side barriers are related to the destruction of infrastructure, social institutions and markets, while demand-side barriers are related to the changes in economic and social structures within families and communities along with the persistent insecurity. The report also discusses the importance of education in achieving stability in conflictaffected countries. It outlines two strategies to support stability through the educational 
system. The first strategy focuses on educating children and young people as agents of positive social change by involving them in several constructive social programs and activities. The second proposed strategy is to build the enabling environment for more effective education by reducing poverty and the need of child labour, reintegrating traumatized kids and kids who experienced interruption in the their education back into the educational system through inclusive educational system, and fostering aspirations by instilling their sense of confidence and by addressing the mental health and cognitive growths for kids who experienced war atrocities to give them the sense of normalcy.

\subsection{Syria Education Sector Analysis}

A recent UNICEF report released in 2016 asses the effects of the crisis on education in Syria between as well as in refugee camps in neighbouring countries in the period of 2011 and 2015 [14]. The study provides both quantitative and qualitative analysis. The quantitative analysis shows that 2.1 million children inside Syria are out of school. The enrolment rates inside Syria dropped by $44 \%$ between 2011 and 2015. As for refugees in neighbouring countries, while the enrolment rate has been decreasing between 2012 and 2015 from $73 \%$ to $53 \%$, in terms of absolute numbers, 627,000 children out of 1.3 million are out of school. The qualitative analysis identifies four main reasons for this drop in enrolment: security and fear, earning money to support the family, education is not a priority (compared to survival), and learning costs. In addition, the qualitative analysis identify several educational challenges including: the decrease in the quality of education caused by the overcrowded classrooms, reduced school hours, and high rate of absenteeism for both students and teachers; the lack of school supplies such as textbooks, classroom boards, stationaries, and other teaching aids; the absence of proper teacher training to deal with emergencies and traumatized children; and the lack of recreational and extracurricular activities and psychosocial support to students.

The study concluded by making several recommendations including: encouraging the active involvement of the parents' community in the education process; increasing the coordination among educational partners in Syria, and sharing evidence-based data, and lessons learned in order to avoid duplicated effort and scale up what works well; promoting psychosocial support through recreational and extracurricular activities, and initiating support group sessions for students and staff; developing creative teaching strategies to deal with the lack of educational resources; supporting the development of selflearning materials for children who are unable to attend school; and extending school hours in safe days to make it up for missed days.

\subsection{One Laptop Per Child (OLPC)}

One laptop per child program was initiated by MIT media lab in 2005. The idea of the program was to provide elementary kids in developing countries with affordable " $\$ 100$ laptops". A number of developing countries adopted the program either as a pilot project for a few schools, or for at a large scale. Currently only a few research work performed formal and informal evaluation of the effectiveness of the program and they show varied findings [15], [16]. 
The program was criticized as being "a laptop" initiative not an educational initiative. Indeed, the program didn't integrate pedagogy at its heart, and it didn't provide guidance on ways to integrate the use of computers into the learning process. Additionally, the program didn't consider the social and cultural context of the deployment environment [17], [18].

Bhatta [19] introduced a framework for implementing the OLPC model. The framework consists of planning and implementation of four key areas: digital contents, teachers' preparation, network and power infrastructure, and the development of the government's capacity in all of the previously mentioned three areas.

\section{Characterizing War-Situation}

When it comes to kids' education during war, war situations can be characterized by the following main traits: insecurity, instability, lack of resources, and lack of adult support and supervision. Each of these trait is described below.

\subsection{Insecurity}

In the absence of security, sending kids to schools becomes a real challenge to parents. Not only the schools are intentionally targeted during conflicts [1], but also the way to the school is not safe. Parents in war face the dilemma of taking the risk of sending their kids to school or keeping them presumably safe at home.

Whether planed or not, kids abduction in the presence of insecurity is very common. In Syria, kids are abducted for two main reasons. In the relatively more secure areas under the Syrian regime control, kids' abduction is performed mainly for financial gains obtained as ransoms from parents. Young adults' abduction, however, is believed to be done by the regime security services as a way to keep the people oppressed and under constant fear, and in many cases abducted people are found dead with signs of torture. In the areas under the control of armed rebels, kids are recruited in the armed conflict as child soldiers which are easily manipulated [24].

Syrians who fled the war in Syria and settled in neighbouring countries also suffer from a different type of insecurity caused by tensions between refugees and host communities, as well as the tension within the refugee camps community caused by the rough conditions of life in refugee camps [20].

\subsection{Instability}

In the insecure war situation, families are frequently displaced looking for a safer place. In many cases they are moving from one neighbourhood to another, from one city to another, and even from one country to another. This shelter instability issue, causes economic, emotional as well social instability for displaced people who had to leave all their belongings and homes behind and settle temporarily in a different shelter within a different society. Additionally, in war situation, the family status is also unstable. In many cases a member of the family is killed, kidnapped, disabled with a war injury, or 
separated from the rest of the family during an attempt to escape bombing or during a clandestine attempt to cross the borders to another country.

In such unstable environment, kids' education is constantly interrupted, and the continuity of the education becomes very challenging with different curricula and different instruction languages. Additionally, with the economic and social instability, older kids are either forced or choose to make survival choices (work, get married, or join militant groups) which don't include education.

\subsection{Lack of Resources}

While the lack of resources is usually one of the reasons behind interstate conflicts, in intrastate conflicts such as in Syria crisis, lack of resources is a consequence of the war. In Syria crisis, there is a clear lack of all resources: food, medical supplies, clothes, fuel, energy sources, educational supplies, and even qualified experts (doctors, engineers, teachers, etc).

The lack of resources inside Syria is caused by the destruction of the agriculture sector (the major economic source in Syria), the difficulty in transporting products, and the regime's enforced siege on some opposition controlled areas. The educational sector is highly affected by this lack of resources. Schools are either destroyed or used as shelters, and school supplies are either limited or not available. Additionally, a number of teachers and administrative staff are either killed, joined the armed conflict, or fled the area. Parents, authorities, and humanitarian organizations are prioritizing spending funds on shelter, food, and medical supplies over school supplies. While resources are relatively available in areas under the Syrian regime control, the prices are usually very high for internally displaced families.

Whether in urban areas or in refugee camps, lack of resources is also an issue for Syrian refugees in neighbouring countries. Most refugee camps are supported by the UNHCR and charitable organizations, however the educational fund they receive is a lot less compared to the actual needs [10].

\subsection{Lack of Adults' Support and Supervision}

As it is always the case in war, it is common to have increased numbers of orphans, kids with single parents, or unaccompanied kids who were separated from their families. In these circumstances, child labour, abuse, and exploitation are common phenomena. Additionally, even when kids live with both parents, the high stress of war affects adults' ability to provide proper parenting [12], [21]. Parents are preoccupied by finding ways for survival. Their focus and priority goes to finding safe shelter, food, and medications, and to keeping their kids alive. Additionally, in many cases parents prioritize work for older kids compared to education.

In such circumstances, kids are either left with no responsible adult who can provide emotional support or educational/behavioural supervision, or with preoccupied stressed parents who are themselves in need of social and psychological support. In such circumstances, kids are vulnerable and are easy subjects of abuse and exploitation. This is why many researchers believe that education doesn't only help children in securing 
decent future, but it also plays a role in distracting kids from the stress of war and it allows them to have a sense of normalcy by following a daily normal life routine of going to school and meeting with other kids and consequently it plays a natural role in lessening the psychological impact of trauma and displacement [12]. Education also plays a role in enhancing the kids chances in getting the appropriate knowledge they need to protect themselves from abuse and to establish their moral code of distinguishing right from wrong.

\section{Design Considerations in war}

In this paper we propose a digital context-aware platform for education in emergencies. The platform emphasizes student' home-based self-learning method with frequent supervision and follow up by a teacher. The platform has four pillars: Hardware, Software, Curriculum, and Supporting Services. The specifications of these pillars are based on three design considerations which are derived from the context of war. The three design considerations are detailed below.

\subsection{Supervised Self-Directed Learning Method}

Given the unique situation of children impacted by war, the system should enable kids to follow their course of study regardless to whether they are physically present at school or not. Due to instability, and insecurity issues, children as well as teachers have high rate of absenteeism. To deal with this on/off situation, the system should be designed so that it can be used independently by the child at home, while at the same time being periodically supervised by a teacher within or outside the context of the school. This would allow children who are unable to attend school (e.g. under siege) to continue their education independently.

In this context, self-directed learning is well suited to allow kids to independently learn from home. While in the general sense, self-directed learning is a learning method followed by adults who have greater autonomy; organization; and motivation; when a pure self-directed learning method is applied with kids it could be problematic. Although the tough conditions of life during war increase the kids' autonomy, and might create fierce eagerness to learn as they view education as their way out of the poor life conditions, children don't have enough life experiences or organizational skills to organize their education within a formal curriculum which lead them to an accredited middle-school or high-school degrees. Accordingly, we suggest complementing the independent learning of kids by a formal periodical supervision performed by an adult educator, hence the term "supervised" is added to "self-directed" learning. In this context, the supervised self-directed learning focuses on allowing the children to independently and flexibly explorer learning materials and resources which are linked to a pre-defined curriculum, while at the same time periodically supervising the kids' learning, and redirecting them towards the curriculum when their learning greatly diverges from the curriculum. 
This suggested learning method has two main implications. First, it suggests implementing a monitoring and follow up mechanism to keep the child on the right track. Consequently, it forms the basis of study continuity for the children, where the teachers can (remotely) follow up individual children progress. In addition, this aspect of supervision adds the formalism required to allow the children's re-integration at school when the situations are more stable. The second implication of supervised self-learning is the need for collaboration and sharing mechanisms to allow effective interaction between the students and the teachers.

This learning method is well suited during emergencies since it mainly focuses on empowering kids with the learning materials they need to perform their study independently, while it requires minimal support and supervision from educators, which means that a small number of teachers can follow up a larger number of students. It also means that children can still follow up their education at their own pace regardless of their conditions: children in hot-zone war, children under siege, young married girls, or working adolescents.

Finally, it is worth noting that the suggested supervised self-learning method with a digital platform focuses on empowering the student with digital self-learning material to be used independently at home, but it doesn't carry any assumptions about the use of the digital platform at school for learning.

\subsection{Context-Aware Education}

We introduce the term "Context-Aware Education" to refer to the education process which takes into consideration the context of the learning environment. In our proposed platform, the context that we want the education to focus on is the "the different possible situations in war context". We, thus, propose this type of education to take into consideration the context of war in two dimensions: the learning outcome dimension, and the learning tools and aids dimension.

In the first dimension, context-aware education expands the learning outcomes of a traditional curriculum to take into consideration the unique situation of the war and of refugee camps. In a traditional educational system, the curriculum is built around: Math, Science, Language Art, and Social Studies, while at the same time, behavioural, and social aspects of the curriculum are implicitly present through the context of the school community and under the supervision of qualified teachers, social workers, and administrators.

In the context of war, where the school society is compromised, behavioural, and social aspects as well as war related concerns should be explicitly integrated into the curriculum. These may include for example: health and safety education, peace and conflictresolution strategies, protection and defence practices, and psychosocial wellness. Indeed, in the long term, today's children's are tomorrow's society builders, and if they are well equipped with the appropriate peace education, the chances of future conflicts can be reduced. Additionally, in the post-conflict period, the community would need well equipped young adults to rebuild the society.

The second dimension of context-aware education deals with the lack of resources available in the learning environment such as school supplies, learning aids, teachers, 
and even learning-time can be viewed as one of the educational resources. Contextaware education deals with the lack of these resources by finding alternatives when these resources are not available. For example, how to teach a 5-yrs old child to hold a pen and write when pencils and papers are not available? How to teach an older child in vocational education how to sew a dress without textiles? How to teach a child a concept without a teacher? How to teach a child a concept in shorter time than originally planned? Based on the context, the 5-yr child can be offered as an alternative to use a stick to trace the letters on the sand or the snow, plastic/paper bags or tree leaves (or any other material available in the surrounding environment) can be offered as an alternative to fabrics, self-learning materials can help a child learn independently, and innovative teaching strategies can help a teacher cover more concepts in shorter time to a larger number of kids. In a digital context, hardcopies of textbooks can be replaced by softcopies, interactive digital forms can replace work-sheets, touch-screen/stylus/digital forms can replace the need for traditional school supplies, etc. Consequently, context-aware education requires creativity approaches in teaching and learning strategies, and it requires adapting the curriculum so that the same learning outcomes can be achieved using alternative learning aids and solutions.

\subsection{Kids-Oriented Design}

As opposed to adults, kids are still in the development process; their physical, cognitive, and emotional abilities keep changing until they become mature adults. Since the main targeted users of the educational system are kids and juniors under 18 years old, who may or may not be supported or supervised by adults, it is important to consider kids' needs, limitations, and challenges when designing the digital education platform. In this context, kids-oriented design goes beyond an appealing user interface for kids.

Kids-Oriented design would address kids' physical abilities, mental/cognitive abilities, and emotional/social abilities. In addition, given the expected lack of adults' support in war situation, the system should be designed to be used independently by the kids while taking into consideration the child's online safety, age-appropriateness of contents, ease of use, as well as automated maintenance and support.

Additionally, with kids-oriented design, the system should be built keeping in mind that “one system doesn't fit all", and it doesn't even fit one child who is developing over time. An appealing system for a 7 years old child will be a boring system for the same child at age 8 , and what works for an 8 years old child will not work for a 15 years old child.

Finally, kids-oriented design would maximize the opportunities to exploit the inquisitive, impatient, adventurous, and creative nature of kids. 


\section{$5 \quad$ Four pillars of the education platform}

Taking into consideration the three design considerations presented in section 4 , the system can be designed based on four pillars: Hardware, Software, Curriculum, and Support.

The hardware should be portable with diverse ways for connectivity (Bluetooth, WiFi, 4G, Ethernet etc.). It should be rugged and energy efficient. The software should be supported by a monitoring and follow-up mechanisms, as well as collaboration and remote access assistance tools. Additionally, a pluggable architecture of the curriculum would allow large scale participation in the development of the curriculum by a large community of educators while keeping the material well-structured according to an approved standard. It is worth noting here that a curriculum in war context should be extended beyond math, language art, science, and foreign languages. For example, an extended curriculum could include health and safety education, peace and conflict resolution principles, child protection and self-defence practices, tolerance and positive citizenship in addition to other topics relevant to the specific context where the system is being used.

Since several curricula are adopted in different areas; inside Syria, in refugee camps, and in bordering countries outside refugee camps [22]; it is almost impossible to use one curriculum in all varying contexts. Consequently, the platform should allow for the flexible integration of different curricula. Regardless of the chosen curriculum, the learning materials should be designed for self-learning.

Finally, in addition to hardware, software, and curriculum, a very critical component to ensure the continuity of using the system is the support services. Support services should consider technical support, educational support, as well as psychosocial support. Such services should not be assumed available on the ground, consequently, the platform should be designed to integrate these services online.

\section{Conclusion}

The presented framework was derived from the body of work done to address education challenges during war. The platform was designed following four steps: (1) Understanding the context of war and extracting the main war characteristics relevant to kids and their education, (2) Extracting strength, weaknesses, and recommendations from the work done in the field of education in war in general and the use of technology as a solution in particular, (3) Adopting three major design considerations based on the extracted recommendations, (4) Specifying the main components of the platform based on the adopted design considerations.

Although the state of the art of all components of the platform shows that the implementation of the platform is feasible, given the extended scale of context-aware education, the implementation process requires massive scale and support to adapt exiting hardware, software, and curriculum to war context in general and to Arabic language and Syrian social community in particular. Consequently, adopting open source soft- 
ware, and keeping the implementation process open to community's as well as volunteers' participation is a key factor in the fast implementation and adoption of the educational system.

Additionally, the cost of the implementation of the platform is clearly another challenge. Assuming active participation of NGOs and volunteers in content development, the major cost attributed to the system would be the price of the hardware (laptops, tablets, solar chargers). The expectation is that for context-aware hardware, the minimum base-line price would be that of OLPC laptops which were engineered to work on poor communities of the developing countries, however OLPC failed to reach the promised $\$ 100$ price.

Finally, despite the challenges, we believe that the benefits of the system outweigh the downsides. In addition, while the presented platform was designed mainly to address Syria crisis, it can be considered as a step toward a sustainable solution for education in emergencies that agencies like UNICEF and UNHCR are looking for.

\section{References}

[1] O'Malley, B. (2010). Education under attack-2010. UNESCO.

[2] Jones, A., \& Naylor, R. (2014). The Quantitative Impact of Armed Conflict on Education: Counting the Human and Financial Cost. CfBT Education Trust.

[3] Unesco. (2011). The Hidden Crisis: Armed Conflict and Education. UNESCO.

[4] Lochner, L. (2004). Education, work, and crime: A human capital approach. International Economic Review, 45(3), 811-843.

[5] Lochner, Lance. "Education and crime." University of Western Ontario 5.8 (2007): $1-14$.

[6] Yoshikawa, Hirokazu. "Long-term effects of early childhood programs on social outcomes and delinquency." The future of children (1995): 51-75.

[7] Machel, Graça. Impact of armed conflict on children. UN, 1996.

[8] P. J. (2014). Barriers to Education in Conflict-Affected Countries: Policy and Opprtunities. Commissioned by UNESCO. Retrieved November 23, 2016, from http://allinschool.org/wp-content/uploads/2015/01/OOSC-2014-Conflict-andeducation-final.pdf

[9] Machel, Graça. The Impact of War on Children: A Review of Progress Since the 1996 United Nations Report on the Impact of Armed Conflict on Children. United Nations Children's Fund, 3 UN Plaza, New York, NY 10017, 2001.

[10] UNICEF (September, 2016). Syria Crisis Report. Retrived from http: https://www.unicef.org/appeals/files/UNICEF_Syria_Crisis_Situation_Report_Se pt_2016.pdf

[11] Global Business Coalition for Education (2016). Exploring the Potential of Technology to Deliver Education \& Skills to Syrian Refugee Youth. GBCE.

[12] Crisp, J., Talbot, C., \& Cipollone, D. B. (2001). Learning for a Future: Refugee Education in Developing Countries. United Nations Publications, Sales \& Marketing Section, Room C-113, Palais des Nations, 1211 Geneva 10, Switzerland.

[13] UNHCR (2014). Innovation at UNHCR - Anything But Business as Ususal. UNHCR. 
[14] Whole of Syria Education Focal Point (2016). Syria Education Sector Analysis. Whole of Syria Education Focal Point.

[15] Cristia, J., Ibarrarán, P., Cueto, S., Santiago, A., \& Severín, E. (2012). Technology and child development: Evidence from the one laptop per child program.

[16] Nugroho, D., \& Lonsdale, M. (2010). Evaluation of OLPC programs global: a literature review.

[17] Kraemer, Kenneth L., Jason Dedrick, and Prakul Sharma. "One laptop per child: vision vs. reality." Communications of the ACM 52, no. 6 (2009): 66-73.

[18] Warschauer, Mark, and Morgan Ames. "Can One Laptop per Child save the world's poor?." Journal of international affairs (2010): 33-51

[19] Bhatta, Saurav Dev. "Tackling the problems of quality and disparity in Nepal's school education: The OLPC Model." Studies in Nepali History and Society 11, no. 1 (2008): 00-00.

[20] UNHCR. Future of Syria. Accessed on November 23, 2016, from http://unhcr.org/FutureOfSyria/

[21] Tolfree, David. Restoring playfulness: different approaches to assisting children who are psychologically affected by war or displacement. Rädda Barnen, 1996.

[22] UNICEF (March 2015). Curriculum, Accreditation and Certification for Syrian Children in Syria, Turkey, Lebanon, Jordan, Iraq and Egypt. UNICEF.

[23] Whole of Syria Education Focal Point. Self-Learning for Out-of-School Children in Syria UNICEF and UNRWA Joint Education Programme. Accessed November 23, 2016 from http://wos-education.org/uploads/selflearning_materials/without_logo/Self_learning_brief_note_Spread_English.pdf 